\title{
Association between methylene tetrahydrofolate reductase and glutathione S-transferase M1 gene polymorphisms and chronic myeloid leukemia in a Brazilian population
}

\author{
G.S. Lordelo ${ }^{1,2}$, A.L. Miranda-Vilela ${ }^{1}$, A.K. Akimoto ${ }^{1}$, P.C.Z. Alves ${ }^{1}$, \\ C.O. Hiragi ${ }^{1}$, A. Nonino ${ }^{2,3}$, M.B. Daldegan ${ }^{2}$, M.N. Klautau-Guimarães ${ }^{1}$ \\ and C.K. Grisolia ${ }^{1}$ \\ ${ }^{1}$ Laboratório de Genética, Departamento de Genética e Morfologia, \\ Instituto de Ciências Biológicas, Universidade de Brasília, Brasília, DF, Brasil \\ ${ }^{2}$ Serviços de Hematologia e Hemoterapia do Hospital de Base do Distrito Federal, \\ Brasília, DF, Brasil \\ ${ }^{3}$ Centro de Oncologia e Hematologia de Brasília, Brasília, DF, Brasil \\ Corresponding author: A.L. Miranda-Vilela \\ E-mail: mirandavilela@unb.br
}

Genet. Mol. Res. 11 (2): 1013-1026 (2012)

Received July 7, 2011

Accepted January 3, 2012

Published April 19, 2012

DOI http://dx.doi.org/10.4238/2012.April.19.6

\begin{abstract}
Chronic myeloid leukemia is a hematopoietic stem cell disorder that causes uncontrolled proliferation of white blood cells. Although the clinical and biological aspects are well documented, little is known about individual susceptibility to this disease. We conducted a case-control study analyzing the prevalence of the polymorphisms MTHFR C677T, MTHFR A1298C, del\{GSTM1\}, del\{GSTT1\}, and haptoglobin in 105 patients with chronic myeloid leukemia (CML) and 273 healthy controls, using PCR-based methods. A significant association with risk of developing CML was found for MTHFR 1298AA (odds ratio $(\mathrm{OR})=1.794 ; 95 \%$ confidence interval $(\mathrm{CI})=$ $1.14-2.83)$ and GSTM1 non-null $(\mathrm{OR}=1.649 ; 95 \% \mathrm{CI}=1.05-2.6)$ genotypes, while MTHFR 1298AC (OR $=0.630 ; 95 \% \mathrm{CI}=0.40$ -
\end{abstract}


$0.99)$ and GSTM1 null (OR $=0.606 ; 95 \% \mathrm{CI}=0.21-0.77)$ genotypes significantly decreased this risk. There appeared to be selection for heterozygosity at the MTHFR 1298 locus. The considerable range of variation in this and other human populations may be a consequence of distinctive processes of natural selection and adaptation to variable environmental conditions. The Brazilian population is very mixed and heterogeneous; we found these two loci to be associated with $\mathrm{CML}$ in this population.

Key words: Chronic myeloid leukemia; Hardy-Weinberg equilibrium; Genetic polymorphisms; Brazilian population; Association study

\section{INTRODUCTION}

Chronic myeloid leukemia (CML) was the first cancer to be associated with a specific cytogenetic marker, the Philadelphia chromosome, resulting from a reciprocal translocation between chromosomes 9 and $22[\mathrm{t}(9 ; 22)(\mathrm{q} 34, \mathrm{q} 11)]$. This translocation transposes the c-abl proto-oncogene from chromosome 9 to the breakpoint cluster region (bcr) on chromosome 22, and this new hybrid bcr-abl oncogene encodes a constitutively active tyrosine-kinase that promotes the growth advantage of leukemia cells through enhanced proliferation and reduced apoptosis, generating genomic instability (Nowicki et al., 2004; Kim et al., 2009).

Although these clinical and biological aspects are well documented, little is known about individual susceptibility to CML. Polymorphic variants of several genes, diet, environmental exposure to carcinogens and individual immune system's characteristics are potential factors that increase predisposition to leukemia (Bowen et al., 2003). Association studies have been performed to identify genetic variants associated with CML susceptibility, and among them are methylenetetrahydrofolate reductase (MTHFR) (Hur et al., 2006; Moon et al., 2007; Barbosa et al., 2008), glutathione S-transferases (GSTs) (Hishida et al., 2005; Souza et al., 2008), and haptoglobin (Hp) gene polymorphisms (Nevo and Tatarsky, 1986; Campregher et al., 2004).

MTHFR, a key enzyme in homocysteine (Hcy) and folate metabolism, plays a role in DNA methylation and provision of nucleotides for DNA synthesis (Ulrich et al., 1999). Mutations in the MTHFR gene may result in enzyme deficiency, low plasma folate levels and hyperhomocysteinemia, a risk factor for coronary and peripheral vascular obstructive events and neural tube defects (Franco et al., 1999). However, under situations of decreased MTHFR activity, more MTHFR substrate is available for purine and pyrimidine synthesis, which may prevent imbalances of nucleotide pools during DNA synthesis and potentially oncogenic alterations in DNA methylation (Ma et al., 1997; Ulrich et al., 1999). Associations have been described between the common MTHFR polymorphisms C677T and A1298C and risk of leukemia (Skibola et al., 1999; Franco et al., 2001; Robien and Ulrich, 2003; Robien et al., 2004; Ismail et al., 2009), but few studies with CML have been published, with inconsistent results (Robien and Ulrich, 2003; Robien et al., 2004; Hur et al., 2006; Kim et al., 2007; Moon et al., 2007; Barbosa et al., 2008; Ismail et al., 2009). Therefore, studies in several ethnicities are required to better understand the biological significance of these 
polymorphisms in CML susceptibility, since they vary among ethnic groups (Franco et al., 1999; Robien and Ulrich, 2003).

The GSTs M1 and T1 genes encode, respectively, for enzymes GST- $\mu$ (mu) and GST$\theta$ (theta), which detoxify environmental carcinogens by glutathione conjugation (Cotton et al., 2000; Souza et al., 2008). Because these genes may be deleted, resulting in deficiency of GST activities (Hengstler et al., 1998) and in diminished ability to detoxify various carcinogens (Crump et al., 2000), environmental exposure to cytotoxic and genotoxic agents could increase CML risk for individuals carrying GST deletions. Indeed, an increased GSTT1 null genotype frequency has been observed in CML patients (Mondal et al., 2005), and GSTM1 polymorphism has been suggested as important in CML etiology (Lourenço et al., 2005). Given interethnic and intra-ethnic differences in GST allele frequencies (Cotton et al., 2000; Landi, 2000), association studies between GSTM1/T1 polymorphisms with CML risk in different ethnicities may help us to better understand the heterogeneity of the disease and of patients' response to treatment.

Susceptibility to leukemia may also be influenced by Hp, a serum glycoprotein that binds free hemoglobin, preventing DNA damage by reactive oxygen species (ROS) (Carter and Worwood, 2007), among other effects. It is known that the $B C R / A B L$ expression stimulates ROS production in hematopoietic progenitor cells (Sattler et al., 2000) and studies have suggested that ROS may contribute to increased DNA damage in CML cells (Nowicki et al., 2004). Because the ability of Hp to block hemoglobin-induced oxidative stress and damage is phenotype dependent (Carter and Worwood, 2007), Hp polymorphism has been investigated in association with leukemia, and the Hp1-1 phenotype has been associated with CML, acute myeloid leukemia (AML) and acute lymphoblastic leukemia (ALL) (Nevo and Tatarsky, 1986; Mitchell et al., 1988). However, the frequency distributions of Hp phenotypes and alleles vary among populations worldwide (Carter and Worwood, 2007), so it is important to run further association studies with CML in different ethnic groups to better evaluate these risks.

The Brazilian population originated from five centuries of interethnic crosses among Europeans, Africans and Amerindians (Alves-Silva et al., 2000). Because this miscegenation can influence the distribution of certain polymorphisms, we aimed to investigate, through a case-control study, a possible association between CML and MTHFR C677T, MTHFR A1298C, del\{GSTM1\}, del\{GSTT1\} and Hp polymorphisms.

\section{MATERIAL AND METHODS}

\section{Study design and participants}

This study consisted of 105 adult CML outpatients of both genders, defined by Philadelphia chromosome and/or $b c r-a b l$ presence, in chronic or accelerated phases (blastic crises or Ph-positive ALL were excluded) and treated in the Hospital de Base (HBDF) in Brasília, Brazil. The control group consisted of 273 non-related healthy volunteers of both genders, recruited in Brasília, among University students, company workers and at HBDF.

This study was conducted under guidelines laid down in the Declaration of Helsinki, and all procedures involving human subjects were approved by the Ethics Committee of the State Health Secretariat of the Federal District (SESDF). Written informed consent was obtained from all registered volunteers. 


\section{Procedures and measurements}

About $5 \mathrm{~mL}$ peripheral blood was collected by venipuncture using Vacutainer tubes with EDTA as anticoagulant for the analyses of gene polymorphisms. Blood samples were centrifuged at $1200 \mathrm{~g}$ for $5 \mathrm{~min}$ at $4^{\circ} \mathrm{C}$. The plasma was removed and DNA was isolated from the buffy-coat (leukocyte fraction) by using a Blood genomicPrep Mini Spin Kit (GE Healthcare, Buckinghamshire, England) purification kit. DNA samples were stored below $-20^{\circ} \mathrm{C}$ until analysis and then underwent amplification in an MJ PTC-100 (MJ Research Inc., Waltham, MA, USA).

\section{Genotyping assay}

MTHFR C677T and MTHFR A1298C genotypes were determined by multiplex polymerase chain reaction (PCR)-based restriction fragment length polymorphism (RFLP) assays performed as described by Yi et al. (2002). The GSTM1 and GSTT1 fragments were amplified simultaneously as proposed by Chen et al. (1996), using $\beta$-globin as positive control. The absence of an amplification product combined with the presence of a positive control band (268-bp DNA fragment of $\beta$-globin) indicated the null variants for both polymorphisms. Hp genotypes were determined by allele-specific PCR as described by Yano et al. (1998).

\section{Statistical analyses}

To verify possible differences in the genotype frequencies between cases and controls, considering the total groups, gender, age groups and skin color, statistical analyses were carried out using SPSS (Statistical Package for the Social Sciences) version 15.0. The continuous variables were tested for normal distribution with Shapiro-Wilk. Possible differences between the two groups were evaluated by the Mann-Whitney U-test, since the data presented heterogeneous variability; values of $\mathrm{P}<0.05$ were considered to be statistically significant.

For the total group and the genetic markers, possible correlations between the parameters gender/age groups, gender/skin color and age groups/skin color were analyzed through the chi-square $\left(\chi^{2}\right)$ correlation test. The odds ratio (OR) with $95 \%$ confidence intervals (CI) was calculated and P values were generated by the Pearson chi-square test. Differences were considered to be significant at $\mathrm{P}<0.05$.

Allelic and genotypic frequencies were estimated by gene counting, and the genotype distribution to Hardy-Weinberg equilibrium (HWE) was assessed by the $\chi^{2}$ test. Values of P $>0.05$ indicated HWE. Data for genetic diversity were assessed by comparing the observed and expected heterozygosities; F-statistics, linkage disequilibrium test for MTHFR C677T and A1298C and for MTHFR and GSTM1 polymorphisms, and probability (P) values were generated using the Genepopweb Statistical Program version 4.1 (http://genepop.curtin.edu. $\mathrm{au})$. The $\chi^{2}$ test was used to compare the genotype frequencies between cases and controls. For dominant markers (GSTM1 and GSTT1), fixation index ( $F_{\text {ST }}$ - F-statistics) was calculated by Arlequin 3.1.1. Since the PCR method is not suitable for distinguishing between homozygous $(+/+$, wild type) and heterozygous (+/-), these two groups were considered together (non-null genotypes) and compared with the variant group (null genotypes). 


\section{RESULTS}

\section{Comparison of the samples from CML and control groups}

The distribution frequencies of MTHFR C677T, GSTT1, and Hp genotypes were similar for control and CML groups, but not for MTHFR A1298C and GSTM1. For MTHFR A1298C, the AA genotype frequency was higher in the CML group and the genotypes containing the variant allele ( $\mathrm{AC}$ and $\mathrm{CC})$ predominated in the control $(\mathrm{P}=0.007)$. For GSTM1, the null genotype presented a significantly higher frequency in the control, while the non-null genotype predominated in the CML group $(\mathrm{P}=0.029)$. For both polymorphisms, these differences were particularly related to females $(\mathrm{P}=0.029$ for MTHFR A1298C and $\mathrm{P}=0.005$ for GSTM1) (Table 1).

\begin{tabular}{|c|c|c|c|c|c|c|c|}
\hline \multirow[t]{2}{*}{ Genetic marker } & \multicolumn{3}{|c|}{ Total } & \multicolumn{2}{|c|}{ Female } & \multicolumn{2}{|c|}{ Male } \\
\hline & Control & & CML & Control & CML & Control & CML \\
\hline \multicolumn{8}{|l|}{ MTHFR C677T } \\
\hline $\mathrm{CC}$ & $140(51.3)$ & & $46(43.8)$ & $68(24.9)$ & $25(23.8)$ & $72(26.4)$ & $21(20)$ \\
\hline CT & $114(41.8)$ & & $47(44.8)$ & $65(23.8)$ & $22(21.0)$ & $49(18.0)$ & $25(23.8)$ \\
\hline TT & $19(7)$ & & $12(11.4)$ & $12(4.4)$ & $4(3.8)$ & $7(2.6)$ & $8(7.6)$ \\
\hline$P$ values & \multicolumn{3}{|c|}{0.125} & \multicolumn{2}{|c|}{0.797} & \multicolumn{2}{|c|}{0.015} \\
\hline \multicolumn{8}{|l|}{ MTHFR A1298C } \\
\hline AA & $119(43.6)$ & & $61(58.1)$ & $54(19.8)$ & $28(26.7)$ & $65(23.8)$ & $33(31.4)$ \\
\hline $\mathrm{AC}$ & $143(52.4)$ & & $43(41)$ & $86(31.5)$ & $22(21.0)$ & $57(20,9)$ & $21(20)$ \\
\hline $\mathrm{CC}$ & $11(4)$ & & $1(1)$ & $5(1.8)$ & $1(1.0)$ & $6(2.2)$ & $0(0)$ \\
\hline$P$ values & \multicolumn{3}{|c|}{0.007} & \multicolumn{2}{|c|}{0.029} & \multicolumn{2}{|c|}{0.139} \\
\hline \multicolumn{8}{|l|}{ GSTM1 } \\
\hline M1- & $176(64.5)$ & & $55(52.4)$ & $95(34.8)$ & $22(21)$ & $81(29.7)$ & $33(31.4)$ \\
\hline M1+ & $97(35.5)$ & & $50(47.6)$ & $50(18.3)$ & $29(27.6)$ & $47(17.2)$ & $21(20)$ \\
\hline P values & \multicolumn{3}{|c|}{0.029} & \multicolumn{2}{|c|}{0.005} & \multicolumn{2}{|c|}{0.738} \\
\hline \multicolumn{8}{|l|}{ GSTT1 } \\
\hline T1- & $65(23.8)$ & & $21(20)$ & $32(11.7)$ & $7(6.7)$ & $33(12.1)$ & $14(13.3)$ \\
\hline $\mathrm{T} 1+$ & $208(76.2)$ & & $84(80)$ & $113(41.4)$ & 44 (41.9) & $95(34.8)$ & $40(38.1)$ \\
\hline$P$ values & \multicolumn{3}{|c|}{0.421} & \multicolumn{2}{|c|}{0.196} & \multicolumn{2}{|c|}{0.984} \\
\hline \multicolumn{8}{|l|}{ Нр } \\
\hline $1 \mathrm{~F}-1 \mathrm{~F}$ & $16(5.9)$ & & $4(3.81)$ & $12(4.4)$ & $1(0.95)$ & $4(1.5)$ & $3(2.86)$ \\
\hline $1 \mathrm{~F}-1 \mathrm{~S}$ & $18(6.6)$ & & $12(11.43)$ & $9(3.3)$ & $7(6.67)$ & $9(3.3)$ & $5(4.76)$ \\
\hline $1 \mathrm{~S}-1 \mathrm{~S}$ & $28(10.3)$ & & $5(4.76)$ & $13(4.8)$ & $3(2.86)$ & $15(5.5)$ & $2(1.9)$ \\
\hline $1 \mathrm{~F}-2$ & $36(13.2)$ & & $13(12.38)$ & $22(8.1)$ & $6(5.71)$ & $14(5.1)$ & $7(6.67)$ \\
\hline $1 \mathrm{~S}-2$ & $93(34.1)$ & & $32(30.48)$ & $46(16.8)$ & $16(15.24)$ & $47(17.2)$ & $16(15.24)$ \\
\hline $2-2$ & $82(30)$ & & $39(37.14)$ & $43(15.8)$ & $18(17.14)$ & $39(14.3)$ & $21(20)$ \\
\hline P values & \multicolumn{3}{|c|}{0.402} & \multicolumn{2}{|c|}{0.455} & \multicolumn{2}{|c|}{0.681} \\
\hline
\end{tabular}

Data are reported as number with percent in parentheses. P values were generated by the Mann-Whitney U-test, using SPSS (Statistical Package for the Social Sciences), version 15.0.

MTHFR A1298C also showed significant difference between the control and CML groups for age 20-40 years $(\mathrm{P}=0.022)$, as did GSTM1 for those over $60(\mathrm{P}=0.006)$ (Table 2). Significant differences in the genotype distribution by skin color were observed only for MTHFR A1298C polymorphism, where AC and CC genotypes were predominant in the white individuals of the control group $(\mathrm{P}=0.017)$ (Table 3$)$. 


\begin{tabular}{|c|c|c|c|c|c|c|}
\hline \multirow[t]{2}{*}{ Genetic marker } & \multicolumn{2}{|c|}{$20-40$ years } & \multicolumn{2}{|c|}{ 41-60 years } & \multicolumn{2}{|c|}{$>60$ years } \\
\hline & Control & CML & Control & CML & Control & $\mathrm{CML}$ \\
\hline \multicolumn{7}{|l|}{ MTHFR C677T } \\
\hline $\mathrm{CC}$ & $91(33.3)$ & $15(14.3)$ & $39(14.3)$ & $23(21.9)$ & $10(3.7)$ & $8(7.6)$ \\
\hline $\mathrm{CT}$ & $73(26.7)$ & $16(15.2)$ & $32(11.7)$ & $19(18.1)$ & $9(3.3)$ & $12(11.4)$ \\
\hline TT & $14(5.1)$ & $5(4.8)$ & $4(1.5)$ & $5(4.8)$ & $1(0.8)$ & $2(1.9)$ \\
\hline P values & \multicolumn{2}{|c|}{0.219} & \multicolumn{2}{|c|}{0.571} & \multicolumn{2}{|c|}{0.352} \\
\hline \multicolumn{7}{|l|}{ MTHFR A1298C } \\
\hline AA & 79 (28.9) & $23(21.9)$ & $31(11.4)$ & $25(23.8)$ & $9(3.3)$ & $13(12.4)$ \\
\hline $\mathrm{AC}$ & $90(33.0)$ & $13(12.4)$ & $42(15.4)$ & $21(20)$ & $11(4.0)$ & $9(8.6)$ \\
\hline $\mathrm{CC}$ & $9(3.3)$ & $0(0)$ & $2(0.7)$ & $1(1.0)$ & $0(0)$ & $0(0)$ \\
\hline$P$ values & \multicolumn{2}{|c|}{0.022} & \multicolumn{2}{|c|}{0.209} & \multicolumn{2}{|c|}{0.367} \\
\hline \multicolumn{7}{|l|}{ GSTM1 } \\
\hline M1- & $113(41.4)$ & $22(21)$ & 49 (17.9) & $27(25.7)$ & $14(5.1)$ & $6(5.7)$ \\
\hline M1+ & $65(23.8)$ & $14(13.3)$ & $26(9.5)$ & $20(19)$ & $6(2.2)$ & $16(15.2)$ \\
\hline$P$ values & \multicolumn{2}{|c|}{0.788} & \multicolumn{2}{|c|}{0.342} & \multicolumn{2}{|c|}{0.006} \\
\hline \multicolumn{7}{|l|}{ GSTT1 } \\
\hline T1- & $45(16.5)$ & $10(9.5)$ & $15(5.5)$ & $10(9.5)$ & $5(1.8)$ & $1(1)$ \\
\hline $\mathrm{T} 1+$ & $133(48.7)$ & $26(24.8)$ & $60(22)$ & $37(35.2)$ & $15(5.5)$ & $21(20)$ \\
\hline$P$ values & \multicolumn{2}{|c|}{0.770} & \multicolumn{2}{|c|}{0.866} & \multicolumn{2}{|c|}{0.062} \\
\hline \multicolumn{7}{|l|}{$\mathrm{Hp}$} \\
\hline $1 \mathrm{~F}-1 \mathrm{~F}$ & $14(5.1)$ & $2(1.9)$ & $2(0.7)$ & $2(1.9)$ & $0(0)$ & $0(0)$ \\
\hline $1 \mathrm{~F}-1 \mathrm{~S}$ & $9(3.3)$ & $5(4.76)$ & $9(3.3)$ & $4(3.81)$ & $0(0)$ & $3(2.86)$ \\
\hline $1 \mathrm{~S}-1 \mathrm{~S}$ & $22(8.1)$ & $1(0.95)$ & $4(1.5)$ & $4(3.81)$ & $1(0.4)$ & $0(0)$ \\
\hline $1 F-2$ & $27(9.9)$ & $5(4.76)$ & $9(3.3)$ & $6(5.71)$ & $0(0)$ & $2(1.9)$ \\
\hline $1 \mathrm{~S}-2$ & $55(20.1)$ & $9(8.57)$ & $27(9.9)$ & $14(13.33)$ & $8(2.9)$ & $9(8.57)$ \\
\hline $2-2$ & $51(18.7)$ & $14(13.33)$ & $24(8.8)$ & $17(16.19)$ & $7(2.6)$ & $8(7.62)$ \\
\hline$P$ values & \multicolumn{2}{|c|}{0.591} & \multicolumn{2}{|c|}{0.816} & \multicolumn{2}{|c|}{0.575} \\
\hline
\end{tabular}

Data are reported as number with percent in parentheses. P values were generated by the Mann-Whitney U-test, using SPSS (Statistical Package for the Social Sciences), version 15.0.

No correlations were found for CML or control for all analyzed parameters. Significantly increased CML risk was shown for MTHFR 1298AA $(\mathrm{OR}=1.794 ; 95 \% \mathrm{CI}=1.14-2.83)$ and GSTM1 non-null $(\mathrm{OR}=1.649 ; 95 \% \mathrm{CI}=1.05-2.6 ; \mathrm{P}=0.031)$. For MTHFR 1298AA, this risk was particularly related to females $(\mathrm{OR}=2.052 ; 95 \% \mathrm{CI}=1.08-3.92 ; \mathrm{P}=0.028)$, age group of $20-40$ years $(\mathrm{OR}=1.980 ; 95 \% \mathrm{CI}=1.06-4.65 ; \mathrm{P}=0.047)$ and white skin color $(\mathrm{OR}$ $=2.218 ; 95 \% \mathrm{CI}=1.09-4.51 ; \mathrm{P}=0.026)$; for $\mathrm{GSTM} 1$, it was related to females $(\mathrm{OR}=2.505$; $95 \% \mathrm{CI}=0.21-0.77 ; \mathrm{P}=0.031)$ and the group $>60$ years $(\mathrm{OR}=6.222 ; 95 \% \mathrm{CI}=1.63-23.76$; $\mathrm{P}=0.006) . \mathrm{Hp} 1 \mathrm{~F}-1 \mathrm{~S}$ individuals of black skin color also presented an increased risk (OR $=$ 7.200; 95\% $\mathrm{CI}=0.94-54.94 ; \mathrm{P}=0.037)$. A decreased $\mathrm{CML}$ risk was observed for MTHFR $1298 \mathrm{AC}(\mathrm{OR}=0.630 ; 95 \% \mathrm{CI}=0.40-0.99 ; \mathrm{P}=0.047)$ and $\mathrm{GSTM} 1$ null $(\mathrm{OR}=0.606 ; 95 \% \mathrm{CI}$ $=0.21-0.77 ; \mathrm{P}=0.031)$, and both were also related to females $(\mathrm{OR}=0.520 ; 95 \% \mathrm{CI}=0.27$ $0.99 ; \mathrm{P}=0.046$ for MTHFR, and $\mathrm{OR}=0.399 ; 95 \% \mathrm{CI}=0.21-0.77 ; \mathrm{P}=0.005$ for GSTM1). For GSTM1 null, it was also related to the group $>60$ years $(\mathrm{OR}=0.161 ; 95 \% \mathrm{CI}=0.04-0.61$; $\mathrm{P}=0.006)$. For males, a decreased risk was observed only for MTHFR 677CC $(\mathrm{OR}=0.495$; $95 \% \mathrm{CI}=0.26-0.95 ; \mathrm{P}=0.032$ ). A decreased risk was also observed for Hp1S-2 individuals of black skin color $(\mathrm{OR}=0.619 ; 95 \% \mathrm{CI}=0.44-0.87 ; \mathrm{P}=0.011)$. 


\begin{tabular}{|c|c|c|c|c|c|c|}
\hline \multirow[t]{2}{*}{ Genetic marker } & \multicolumn{2}{|c|}{ White } & \multicolumn{2}{|c|}{ Mulatto ("Pardo") } & \multicolumn{2}{|c|}{ Black } \\
\hline & Control & CML & Control & CML & Control & CML \\
\hline \multicolumn{7}{|l|}{ MTHFR C677T } \\
\hline $\mathrm{CC}$ & $74(27.1)$ & $15(14.39)$ & $46(16.9)$ & $25(23.8)$ & $20(7.3)$ & $6(5.7)$ \\
\hline $\mathrm{CT}$ & $66(24.2)$ & $21(20)$ & $42(15.4)$ & 24 (22.9) & $6(2.2)$ & $2(1.9)$ \\
\hline TT & $15(5.5)$ & $5(4.8)$ & $3(1.1)$ & $7(6.7)$ & $1(0.4)$ & $0(0)$ \\
\hline$P$ values & \multicolumn{2}{|c|}{0.215} & \multicolumn{2}{|c|}{0.243} & \multicolumn{2}{|c|}{0.918} \\
\hline \multicolumn{7}{|c|}{ MTHFR A1298C } \\
\hline AA & $68(24.9)$ & $26(24.8)$ & $36(13.2)$ & $29(27.6)$ & $15(5.5)$ & $6(5.7)$ \\
\hline $\mathrm{AC}$ & $79(28.9)$ & $15(14.3)$ & $54(19.8)$ & $26(24.8)$ & $10(3.7)$ & $2(1.9)$ \\
\hline $\mathrm{CC}$ & $8(2.9)$ & $0(0)$ & $1(0.4)$ & $1(1.0)$ & $2(0.7)$ & $0(0)$ \\
\hline $\mathrm{P}$ values & \multicolumn{2}{|c|}{0.017} & \multicolumn{2}{|c|}{0.171} & \multicolumn{2}{|c|}{0.295} \\
\hline \multicolumn{7}{|l|}{ GSTM1 } \\
\hline M1- & $101(37)$ & $21(20)$ & $61(22.3)$ & $31(29.5)$ & $14(5.1)$ & $3(2.9)$ \\
\hline M1+ & $54(19.8)$ & $20(19)$ & $30(11)$ & $25(23.8)$ & $13(4.8)$ & $5(4.8)$ \\
\hline$P$ values & \multicolumn{2}{|c|}{0.102} & \multicolumn{2}{|c|}{0.139} & \multicolumn{2}{|c|}{0.482} \\
\hline \multicolumn{7}{|l|}{ GSTT1 } \\
\hline T1- & 37 (13.6) & $5(4.8)$ & $24(8.8)$ & $16(15.2)$ & $4(1.5)$ & $0(0)$ \\
\hline $\mathrm{T} 1+$ & $118(43.2)$ & $36(34.3)$ & $67(24.5)$ & $40(38.1)$ & $23(8.4)$ & $8(7.6)$ \\
\hline $\mathrm{P}$ values & \multicolumn{2}{|c|}{0.106} & \multicolumn{2}{|c|}{0.804} & \multicolumn{2}{|c|}{0.254} \\
\hline \multicolumn{7}{|l|}{$\mathrm{Hp}$} \\
\hline $1 \mathrm{~F}-1 \mathrm{~F}$ & $7(2.6)$ & $2(1.9)$ & $8(2.9)$ & $1(0.95)$ & $1(0.4)$ & $1(0.95)$ \\
\hline $1 \mathrm{~F}-1 \mathrm{~S}$ & $9(3.3)$ & $2(1.9)$ & $7(2.6)$ & $7(6.67)$ & $2(0.7)$ & $3(2.86)$ \\
\hline $1 \mathrm{~S}-1 \mathrm{~S}$ & $11(4)$ & $2(1.9)$ & $13(4.8)$ & $3(2.86)$ & $4(1.5)$ & $0(0)$ \\
\hline $1 F-2$ & $24(8.8)$ & $5(4.76)$ & $11(4)$ & $6(5.71)$ & $1(0.4)$ & $2(1.9)$ \\
\hline $1 \mathrm{~S}-2$ & $54(19.8)$ & $13(12.38)$ & $26(9.5)$ & $19(18.1)$ & $13(4.8)$ & $0(0)$ \\
\hline $2-2$ & $51(18.7)$ & $17(16.19)$ & $26(9.5)$ & $20(19.05)$ & $5(1.8)$ & $2(1.9)$ \\
\hline$P$ values & \multicolumn{2}{|c|}{0.342} & \multicolumn{2}{|c|}{0.209} & \multicolumn{2}{|c|}{0.067} \\
\hline
\end{tabular}

Data are reported as number with percent in parentheses. P values were generated by the Mann-Whitney U-test, using SPSS (Statistical Package for the Social Sciences), version 15.0.

\section{Population statistics}

Significant deviations from HWE were observed for MTHFR A1298C in both groups $(\mathrm{P}=0.0000$ for controls and $\mathrm{P}=0.0374$ for $\mathrm{CML}$ ), for GSTM1 and GSTT1 ( $\mathrm{P}=$ 0.000 for both $)$, and for $\mathrm{Hp}(\mathrm{P}=0.0022)$ in the control group. For MTHFR A1298C, this was compatible with heterozygote excess $(\mathrm{P}=0.000$ for control and $\mathrm{P}=0.0217$ for $\mathrm{CML})$; for GSTs, with heterozygote deficit, probably due to wild-type homozygous and heterozygous being considered together within non-null genotypes. For Hp, deviation from HWE was in conformity with heterozygote deficiency in the control group $(\mathrm{P}=0.0374)$ (Tables 4 and 5). In the two groups a strong linkage disequilibrium was detected between MTHFR C677T and A1298C loci $(\mathrm{P}<0.001$ for control and CML), but not between MTHFR (C677T or A1298C) and GSTM1 loci.

Results of F-statistics indicated a slight genetic differentiation for MTHFR 1298 $\left(F_{\mathrm{ST}}=0.0166\right)$ and GSTM1 $\left(F_{\mathrm{ST}}=0.0238\right)$ loci, being in conformity with selection in favor of heterozygotes for MTHFR 1298 locus $\left(F_{\text {IS }}=-0.2334 ; F_{\text {IT }}=-0.2130\right)$. However, no substructuring was observed $\left(F_{\mathrm{ST}}=0.0088\right)$ for the population. Homogenous distribution of MTHFR C677T, GSTT1 and Hp genotypes in both groups, and heterogeneous distribution for MTHFR A1298C ( $\mathrm{P}=0.0221)$ and GSTM1 $(\mathrm{P}=0.0308)$ loci were observed (Table 5). 
G.S. Lordelo et al.

1020

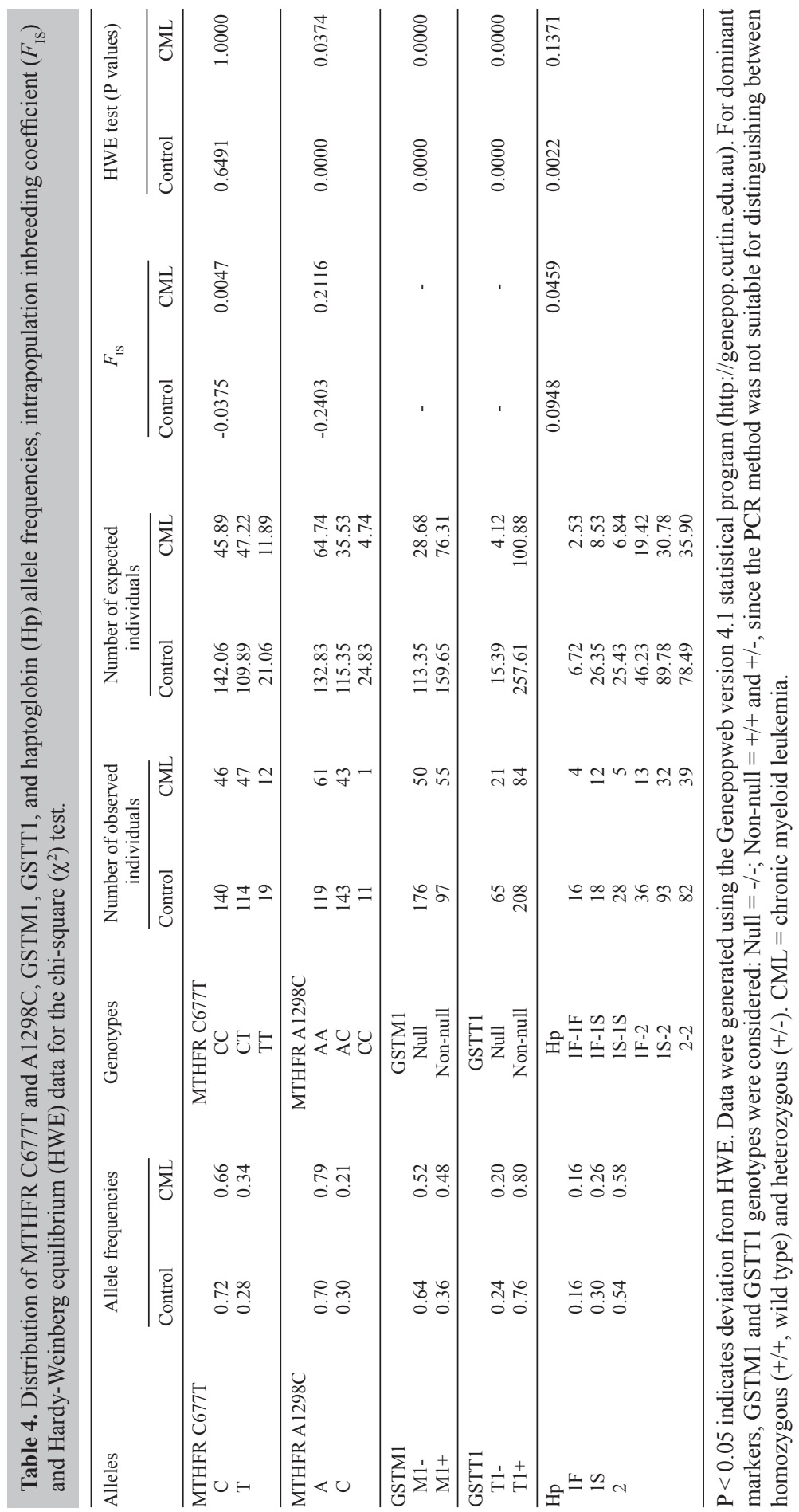

Genetics and Molecular Research 11 (2): 1013-1026 (2012)

CFUNPEC-RP www.funpecrp.com.br 


\begin{tabular}{|c|c|c|c|c|c|c|c|c|}
\hline \multirow[t]{2}{*}{ Genetic marker } & \multicolumn{2}{|c|}{ Observed heterozygosity } & \multicolumn{2}{|c|}{ Expected heterozygosity } & \multirow[t]{2}{*}{$F_{\text {IS }}$} & \multirow[t]{2}{*}{$F_{\mathrm{ST}}$} & \multirow[t]{2}{*}{$F_{\mathrm{IT}}$} & \multirow[t]{2}{*}{ Heterogeneity test (P values) } \\
\hline & Control & CML & Control & CML & & & & \\
\hline MTHFR C677T & 0.4176 & 0.4476 & 0.4032 & 0.4488 & -0.0249 & 0.0053 & -0.0195 & 0.2384 \\
\hline MTHFR A1298C & 0.5238 & 0.4095 & 0.4200 & 0.3318 & -0.2334 & 0.0166 & -0.2130 & 0.0221 \\
\hline GSTM1 & - & - & - & - & - & 0.0238 & - & 0.0308 \\
\hline GSTT1 & - & - & - & - & - & -0.0024 & - & 0.4288 \\
\hline Hp & 0.5385 & 0.5429 & 0.5928 & 0.5704 & 0.0817 & 0.0005 & 0.0822 & 0.2215 \\
\hline Total & & & & & -0.0396 & 0.0088 & -0.0327 & \\
\hline
\end{tabular}

For co-dominant markers, F-statistics data were generated by the Genepopweb version 4.1 statistical program (http://genepop.curtin.edu.au). For dominant markers GSTM1 and GSTT1, $F_{\mathrm{ST}}$ data were generated by the Arlequin v. 3.1.1 statistical program. For these markers, Null $=-/-$; Non-null $=+/+$ and $+/$ - were considered, since the PCR method was not suitable for distinguishing between homozygous (+/+, wild type) and heterozygous (+/-).

\section{DISCUSSION}

Populations worldwide vary considerably in their predisposition to diseases and in the allele frequencies of pharmacogenetically important loci, probably due to genetic drift or adaptation to local selective factors such as climate and available nutrients (Suarez-Kurtz, 2004), and our results corroborate this. MTHFR catalyzes the irreversible conversion of 5,10-methylenetetrahydrofolate to 5-methyltetrahydrofolate (Duthie et al., 2002; Moon et al., 2007), serving as methyl donor in remethylation of Hcy to methionine, which in turn is converted to S-adenosylmethionine (SAM) that methylates specific cytosines in DNA, regulating gene transcription (Duthie et al., 2002).

In this study, the MTHFR 1298 wild-type genotype (AA) was linked to significantly increased risk of developing CML, mainly for young adult females, while 1298AC significantly decreased this risk; no association was found for the C677T polymorphism, although a lower risk was shown for men carrying the $677 \mathrm{CC}$ genotype. The A1298C polymorphism lies in the SAM-regulatory domain of the enzyme, and folate affects gene expression, regulating cellular SAM levels (Duthie et al., 2002). Bearing this in mind, results support the idea that, at least for our population, MTHFR 1298 heterozygosis may give an adaptive advantage to individuals, possibly making its carriers less sensitive to folate necessity to regulate gene transcription than the carriers of the wild-type genotype.

Because SAM regulates gene transcription through methylation, as a consequence of folate deficiency, SAM is depleted, inducing DNA hypomethylation and, potentially, protooncogene expression leading to cancer (Duthie et al., 2002). Although this study did not assess folate or Hcy levels, neither the 1298CC nor the heterozygous state has been associated with higher plasma Hcy or lower plasma folate concentration, phenomena evident with homozygosity 677TT (van der Put et al., 1998). Moreover, a decreased CML risk in Asians (Hur et al., 2006) and fewer relapses after bone marrow transplant in Caucasians (Robien et al., 2004) have been observed for the 1298AC genotype.

The $\mathrm{C}$ allele frequency of MTHFR 1298 ranges from 0.17-0.19 among Asians to 0.27-0.36 in Western Europe. Little is known about A1298C allele frequencies among African or South American populations (Robien and Ulrich, 2003), justifying the importance of this 
study. The $\mathrm{C}$ allele frequency of our control group (0.30) was within frequencies reported in Western Europe, while for the CML group, this (0.21) was close to those found in South Africa (Robien and Ulrich, 2003), despite an increased risk for white-skinned 1298AA carriers. Miscegenation in Brazil may have influenced distribution of this polymorphism. Consequently, identifying genetic components that can contribute to developing CML in the Brazilian population may help increase understanding of variability in disease course and in patients' response to medication in our population, improving treatment strategies. Because the Federal District was formed by migrants from all Brazilian regions (Queiroz, 2006), its population reflects the overall constitution of the Brazilian population better than populations of other Brazilian regions.

Variation in human populations may reflect natural selection and adaptation to environmental conditions (Barreiro et al., 2008). Deviations from HWE might be explained by natural selection or recent ethnic admixture (Barreiro et al., 2008), but the latter is not the case here. Instead, significant deviation from HWE for the MTHFR 1298 locus was compatible with heterozygote excess, indicating that heterozygosis may provide an adaptive advantage. Moreover, MTHFR C677T and A1298C have been found to be in strong linkage disequilibrium (Robien and Ulrich, 2003), corroborating our results; nevertheless, no association with CML was found for MTHFR 677 locus.

Population growth and positive selection increase the proportion of rare alleles, whereas balancing selection and population substructure increases the proportion of intermediate alleles (Serre and Hudson, 2006). In this study, control and CML groups were genetically homogeneous for MTHFR C677T, GSTT1 and Hp loci. Moreover, the fixation index $\left(F_{\mathrm{ST}}\right)$, which measures the degree of genetic differentiation of subpopulations (Nei, 1977), indicated no sub-structuring of the Brazilian population under study, despite the slight genetic differentiation for MTHFR 1298 and GSTM1 loci, which reflect the associations found.

Natural selection can act at the level of genes, if particular genotypes allow for increased fitness in specific environments. Genes under positive selection are thought to have an important role in human survival and to affect complex phenotypes of medical relevance (Barreiro et al., 2008). In this study, an association with the risk of developing CML was found for MTHFR 1298AA and GSTM1 non-null genotypes in all statistical tests performed, particularly for women, and these findings are supported by the literature. Because MTHFR directs the flux of intracellular folate toward the conversion of Hcy to methionine at the expense of nucleotide synthesis (Robien et al., 2004), folate deficiency has been associated with uracil misincorporation into DNA and DNA double-strand breaks during uracil excision repair, thus increasing the risk of chromosomal aberrations (Robien and Ulrick, 2003). Moreover, folate deficiency, as observed by alcohol consumption, affects cellular SAM and Hcy levels (Ma et al., 1997; Duthie et al., 2002), and Hcy has been suggested as a marker for cancer (Ozkan et al., 2007). SAM may act as a physiological antidote against estrogen hepatobiliary toxicity in susceptible women (Frezza et al., 1988), and increased total Hcy may decrease folate levels and total glutathione (Ozkan et al., 2007), a tripeptide essential for removal of hydrogen and lipid peroxides from cells by glutathione peroxidases and for detoxifying environmental carcinogens by GSTs (Rover Júnior et al., 2001).

Our study used a PCR method that did not distinguish between non-null homozygous and heterozygous in GST genotyping, but this is a standard method in the literature, with some variations. Moreover, the GSTM1 non-null genotype has already been reported in a higher 
frequency in CML patients than in controls among Japanese (Hishida et al., 2005). None of the published articles have performed OR or association studies using GSTM1 non-null genotype; they have only analyzed the CML risk for the GSTM1 null genotype or in combination with GSTT1 (Hishida et al., 2005; Lourenço et al., 2005; Mondal et al., 2005; Souza et al., 2008). This may be because it is unbelievable that the presence of an enzyme, which operates in carcinogen detoxification, could increase cancer risk, while its lack could protect against it. However, there are also two other alleles at the GSTM1 locus, GSTM1a and GSTM1b, which differ by a substitution in one base pair (Cotton et al., 2000). Although it is believed that there are no functional differences between them (Cotton et al., 2000), these assumptions may be unjustified, since individuals with two positive alleles may be better protected than GSTM1 heterozygotes for null genotypes (Fryer et al., 1993), which could justify the association found in this study. Thus, this needs further investigation.

Moreover, besides interethnic differences in GSTM1 allele frequencies, there are also intra-ethnic differences. In healthy individuals, GSTM1 homozygous nulls have been reported in $22-67 \%$ of individuals worldwide in different ethnicities, with lower frequencies in African Americans and Indians and higher frequencies in Caucasians and Asians (Rebbeck, 1997; Hiragi et al., 2011), although 64-100\% have been reported in Oceania (Rebbeck, 1997; Cotton et al., 2000). In Brazilian Afro-descendants, these frequencies are 47-58\% (Rebbeck, 1997; Hiragi et al., 2011); in Amerindians, 52-55\% (Hiragi et al., 2011), and in urban Brazilian populations, 35-63\% (Maciel et al., 2009; Miranda-Vilela et al., 2010; Hiragi et al., 2011).

Although the GSTM1 locus is located near the MTHFR locus, there was no linkage disequilibrium between these loci. However, selection in another gene located close to the GSTM1 gene cannot be discarded. The GSTM1 locus (1p13.3) is close to the NRAS locus (1p13.2), a proto-oncogene in the p21 RAS subfamily of small GTPases, which regulates cell proliferation, cytoskeletal organization, and other signaling networks and is the most frequent target of activating mutations in cancer (Oliveira et al., 2007). The NRAS oncogene activated by a point mutation is implicated in various human tumors, including AML and CML (Chin et al., 1992). Although we have not genotyped the NRAS gene, a linkage disequilibrium between NRAS and GSTM1 loci could be possible. This is mainly because our study also showed increased CML risk for $>60$ years, and the incidence of cancer increases with age, due mainly to longer exposure to carcinogens (Anisimov, 2007). Thus, GSTM1 and NRAS loci need to be investigated together in the context of cancer, concerning possible linkage disequilibrium, to avoid spurious associations.

Because the expression of $B C R / A B L$ stimulates ROS production, which may contribute to increased DNA damage in CML cells (Sattler et al., 2000; Nowicki et al., 2004), the Hp polymorphism has been investigated in leukemias, and the Hp1-1 phenotype has been associated with increased risk (Nevo and Tatarsky, 1986; Mitchell et al., 1988; Campregher et al., 2004). Despite the small sample size and large confidence interval, results indicated increased CML risk for Hp1F-1S individuals of black skin color and decreased risk for the same group carrying the Hp1S-2 genotype. Because the deviation from HWE was mainly due to a higher number of $1 \mathrm{~F}-1 \mathrm{~F}$ and a lower number of $1 \mathrm{~F}-1 \mathrm{~S}$ and $1 \mathrm{~F}-2$ individuals than expected, results indicate that there are differences in biological responses among the $\mathrm{Hp}^{{ }^{* 1}}$ alleles and that they cannot be treated as a single block in the association studies.

In conclusion, an association with a risk of developing CML was found for MTHFR 1298AA and GSTM1 non-null genotypes, while MTHFR 1298AC and GSTM1 null geno- 
types decreased this risk in all statistical tests performed. Results also indicated selection in favor of heterozygous for the MTHFR 1298 locus. Because the considerable range of variation in human populations may reflect natural selection, and as the Brazilian population is miscegenated, results indicated that, at least for our population, these two loci are important in the CML context, needing further investigation alongside folate dosages and clinical data.

\section{ACKNOWLEDGMENTS}

The authors gratefully acknowledge the subjects who participated in this research, the HBDF and UnB, the National Council for Technological and Scientific Development (CNPq), the Coordination for Further Training of Graduate Staff (CAPES) and the Scientific and Technological Enterprises Foundation (FINATEC) for making this research possible.

\section{REFERENCES}

Alves-Silva J, da Silva SM, Guimaraes PE, Ferreira AC, et al. (2000). The ancestry of Brazilian mtDNA lineages. Am. J. Hum. Genet. 67: 444-461.

Anisimov VN (2007). Biology of aging and cancer. Cancer Control 14: 23-31.

Barbosa CG, Souza CL, Moura Neto JP, Arruda MGB, et al. (2008). Methylenetetrahydrofolate reductase polymorphisms in myeloid leukemia patients from Northeastern Brazil. Genet. Mol. Biol. 31: 29-32.

Barreiro LB, Laval G, Quach H, Patin E, et al. (2008). Natural selection has driven population differentiation in modern humans. Nat. Genet. 40: 340-345.

Bowen DT, Frew ME, Rollinson S, Roddam PL, et al. (2003). CYP1A1*2B (Val) allele is overrepresented in a subgroup of acute myeloid leukemia patients with poor-risk karyotype associated with NRAS mutation, but not associated with FLT3 internal tandem duplication. Blood 101: 2770-2774.

Campregher PV, Lorand-Metze I, Grotto HZW and Sonati MF (2004). Haptoglobin phenotypes in Brazilian patients with leukemia. Braz. J. Pathol. Lab. Med. 40: 307-309.

Carter K and Worwood M (2007). Haptoglobin: a review of the major allele frequencies worldwide and their association with diseases. Int. J. Lab. Hematol. 29: 92-110.

Chen CL, Liu Q and Relling MV (1996). Simultaneous characterization of glutathione S-transferase M1 and T1 polymorphisms by polymerase chain reaction in American whites and blacks. Pharmacogenetics 6: 187-191.

Chin YM, Bosco JJ and Koh CL (1992). Analysis of ras gene mutations in acute myeloid leukemia by the polymerase chain reaction and oligonucleotide probes. Singapore Med. J. 33: 48-50.

Cotton SC, Sharp L, Little J and Brockton N (2000). Glutathione S-transferase polymorphisms and colorectal cancer: a HuGE review. Am. J. Epidemiol. 151: 7-32.

Crump C, Chen C, Appelbaum FR, Kopecky KJ, et al. (2000). Glutathione S-transferase theta 1 gene deletion and risk of acute myeloid leukemia. Cancer Epidemiol. Biomarkers Prev. 9: 457-460.

Duthie SJ, Narayanan S, Brand GM, Pirie L, et al. (2002). Impact of folate deficiency on DNA stability. J. Nutr. 132: 2444S-2449S.

Franco RF, Morelli V, Lourenco D, Maffei FH, et al. (1999). A second mutation in the methylenetetrahydrofolate reductase gene and the risk of venous thrombotic disease. Br. J. Haematol. 105: 556-559.

Franco RF, Simoes BP, Tone LG, Gabellini SM, et al. (2001). The methylenetetrahydrofolate reductase C677T gene polymorphism decreases the risk of childhood acute lymphocytic leukaemia. Br. J. Haematol. 115: 616-618.

Frezza M, Tritapepe R, Pozzato G and Di Padova C (1988). Prevention of S-adenosylmethionine of estrogen-induced hepatobiliary toxicity in susceptible women. Am. J. Gastroenterol. 83: 1098-1102.

Fryer AA, Zhao L, Alldersea J, Pearson WR, et al. (1993). Use of site-directed mutagenesis of allele-specific PCR primers to identify the GSTM1 A, GSTM1 B, GSTM1 A,B and GSTM1 null polymorphisms at the glutathione S-transferase, GSTM1 locus. Biochem. J. 295: 313-315.

Hengstler JG, Arand M, Herrero ME and Oesch F (1998). Polymorphisms of N-acetyltransferases, glutathione S-transferases, microsomal epoxide hydrolase and sulfotransferases: influence on cancer susceptibility. Recent Results Cancer Res. 154: 47-85.

Hiragi CO, Miranda-Vilela AL, Rocha DMS, Oliveira SF, et al. (2011). Superoxide dismutase, catalase, glutathione 
peroxidase and gluthatione S-transferases M1 and T1 gene polymorphisms in three Brazilian population groups. Genet. Mol. Biol. 34: 11-18.

Hishida A, Terakura S, Emi N, Yamamoto K, et al. (2005). GSTT1 and GSTM1 deletions, NQO1 C609T polymorphism and risk of chronic myelogenous leukemia in Japanese. Asian Pac. J. Cancer Prev. 6: 251-255.

Hur M, Park JY, Cho HC, Lee KM, et al. (2006). Methylenetetrahydrofolate reductase A1298C genotypes are associated with the risks of acute lymphoblastic leukaemia and chronic myelogenous leukaemia in the Korean population. Clin. Lab. Haematol. 28: 154-159.

Ismail SI, Ababneh NA and Awidi A (2009). Methylenetetrahydrofolate reductase (MTHFR) genotype association with the risk of chronic myelogenous leukemia. Jordan Med. J. 43: 8-14.

Kim DH, Xu W, Ma C, Liu X, et al. (2009). Genetic variants in the candidate genes of the apoptosis pathway and susceptibility to chronic myeloid leukemia. Blood 113: 2517-2525.

Kim I, Lee KH, Kim JH, Ra EK, et al. (2007). Polymorphisms of the methylenetetrahydrofolate reductase gene and clinical outcomes in HLA-matched sibling allogeneic hematopoietic stem cell transplantation. Ann. Hematol. 86: 41-48.

Landi S (2000). Mammalian class theta GST and differential susceptibility to carcinogens: a review. Mutat. Res. 463: 247-283.

Lourenço GJ, Ortega MM, Nascimento H, Teori MT, et al. (2005). Polymorphisms of glutathione S-transferase mu1 (GSTM1) and theta 1 (GSTT1) genes in chronic myeloid leukaemia. Eur. J. Haematol. 75: 530-531.

Ma J, Stampfer MJ, Giovannucci E, Artigas C, et al. (1997). Methylenetetrahydrofolate reductase polymorphism, dietary interactions, and risk of colorectal cancer. Cancer Res. 57: 1098-1102.

Maciel ME, Oliveira FK, Propst GB, Bicalho MG, et al. (2009). Population analysis of xenobiotic metabolizing genes in South Brazilian Euro and Afro-descendants. Genet. Mol. Biol. 32: 723-728.

Miranda-Vilela AL, Alves PC, Akimoto AK, Lordelo GS, et al. (2010). Gene polymorphisms against DNA damage induced by hydrogen peroxide in leukocytes of healthy humans through comet assay: a quasi-experimental study. Environ. Health 9: 21.

Mitchell RJ, Carzino R and Janardhana V (1988). Associations between the two serum proteins haptoglobin and transferrin and leukaemia. Hum. Hered. 38: 144-150.

Mondal BC, Paria N, Majumdar S, Chandra S, et al. (2005). Glutathione S-transferase M1 and T1 null genotype frequency in chronic myeloid leukaemia. Eur. J. Cancer Prev. 14: 281-284.

Moon HW, Kim TY, Oh BR, Min HC, et al. (2007). MTHFR 677CC/1298CC genotypes are highly associated with chronic myelogenous leukemia: a case-control study in Korea. Leuk. Res. 31: 1213-1217.

Nei M (1977). F-statistics and analysis of gene diversity in subdivided populations. Ann. Hum. Genet. 41: 225-233.

Nevo S and Tatarsky I (1986). Serum haptoglobin types and leukemia. Hum. Genet. 73: 240-244.

Nowicki MO, Falinski R, Koptyra M, Slupianek A, et al. (2004). BCR/ABL oncogenic kinase promotes unfaithful repair of the reactive oxygen species-dependent DNA double-strand breaks. Blood 104: 3746-3753.

Oliveira JB, Bidere N, Niemela JE, Zheng L, et al. (2007). NRAS mutation causes a human autoimmune lymphoproliferative syndrome. Proc. Natl. Acad. Sci. U. S. A. 104: 8953-8958.

Ozkan Y, Yardim-Akaydin S, Firat H, Caliskan-Can E, et al. (2007). Usefulness of homocysteine as a cancer marker: total thiol compounds and folate levels in untreated lung cancer patients. Anticancer Res. 27: 1185-1189.

Queiroz EP (2006). A Migração Intrametropolitana no Distrito Federal e Entorno: O Conseqüente Fluxo Pendular e o Uso dos Equipamentos Urbanos de Saúde e Educação. Available at [http:/www.abep.nepo.unicamp.br/encontro2006/ docspdf/ABEP2006_724.pdf]. Accessed May 6, 2011.

Rebbeck TR (1997). Molecular epidemiology of the human glutathione S-transferase genotypes GSTM1 and GSTT1 in cancer susceptibility. Cancer Epidemiol. Biomarkers Prev. 6: 733-743.

Robien K and Ulrich CM (2003). 5,10-Methylenetetrahydrofolate reductase polymorphisms and leukemia risk: a HuGE minireview. Am. J. Epidemiol. 157: 571-582.

Robien K, Ulrich CM, Bigler J, Yasui Y, et al. (2004). Methylenetetrahydrofolate reductase genotype affects risk of relapse after hematopoietic cell transplantation for chronic myelogenous leukemia. Clin. Cancer Res. 10: 7592-7598.

Rover Júnior L, Höehr NF, Vellasco AP and Kubota LT (2001). Sistema antioxidante envolvendo o ciclo metabólico da glutationa associado a métodos eletroanalíticos na avaliação do estresse oxidativo. Quim. Nova 24: 112-119.

Sattler M, Verma S, Shrikhande G, Byrne CH, et al. (2000). The BCR/ABL tyrosine kinase induces production of reactive oxygen species in hematopoietic cells. J. Biol. Chem. 275: 24273-24278.

Serre D and Hudson TJ (2006). Resources for genetic variation studies. Annu. Rev. Genomics Hum. Genet. 7: 443-457.

Skibola CF, Smith MT, Kane E, Roman E, et al. (1999). Polymorphisms in the methylenetetrahydrofolate reductase gene are associated with susceptibility to acute leukemia in adults. Proc. Natl. Acad. Sci. U. S. A. 96: 12810-12815.

Souza CL, Barbosa CG, Neto JPM, Barreto JH, et al. (2008). Polymorphisms in the glutathione S-transferase theta and $m u$ genes and susceptibility to myeloid leukemia in Brazilian patients. Genet. Mol. Biol. 31: 39-41.

Genetics and Molecular Research 11 (2): 1013-1026 (2012)

CFUNPEC-RP www.funpecrp.com.br 
Suarez-Kurtz G (2004). Pharmacogenomics in admixed populations: the Brazilian pharmacogenetics/pharmacogenomics network - REFARGEN. Pharmacogenomics J. 4: 347-348.

Ulrich CM, Kampman E, Bigler J, Schwartz SM, et al. (1999). Colorectal adenomas and the C677T MTHFR polymorphism: evidence for gene-environment interaction? Cancer Epidemiol. Biomarkers Prev. 8: 659-668.

van der Put NM, Gabreels F, Stevens EM, Smeitink JA, et al. (1998). A second common mutation in the methylenetetrahydrofolate reductase gene: an additional risk factor for neural-tube defects? Am. J. Hum. Genet. 62: 1044-1051.

Yano A, Yamamoto Y, Miyaishi S and Ishizu H (1998). Haptoglobin genotyping by allele-specific polymerase chain reaction amplification. Acta Med. Okayama 52: 173-181.

Yi P, Pogribny I and Jill JS (2002). Multiplex PCR for simultaneous detection of $677 \mathrm{C} \rightarrow \mathrm{T}$ and $1298 \mathrm{~A} \rightarrow \mathrm{C}$ polymorphisms in methylenetetrahydrofolate reductase gene for population studies of cancer risk. Cancer Lett. 181: 209. 